\title{
Technologies to Support Community Flood Disaster Risk Reduction
}

\author{
Ian McCallum ${ }^{1} \cdot$ Wei Liu ${ }^{1} \cdot$ Linda See $^{1} \cdot$ Reinhard Mechler $^{1} \cdot$ Adriana Keating $^{1} \cdot$ \\ Stefan Hochrainer-Stigler ${ }^{1} \cdot$ Junko Mochizuki $^{1} \cdot$ Steffen Fritz $^{1} \cdot$ Sumit Dugar $^{2}$. \\ Miguel Arestegui ${ }^{3} \cdot$ Michael Szoenyi $^{4} \cdot$ Juan-Carlos Laso Bayas $^{1} \cdot$ Peter Burek $^{1}$. \\ Adam French $^{1} \cdot$ Inian Moorthy ${ }^{1}$
}

Published online: 17 June 2016

(C) The Author(s) 2016. This article is published with open access at Springerlink.com

\begin{abstract}
Floods affect more people globally than any other type of natural hazard. Great potential exists for new technologies to support flood disaster risk reduction. In addition to existing expert-based data collection and analysis, direct input from communities and citizens across the globe may also be used to monitor, validate, and reduce flood risk. New technologies have already been proven to effectively aid in humanitarian response and recovery. However, while ex-ante technologies are increasingly utilized to collect information on exposure, efforts directed towards assessing and monitoring hazards and vulnerability remain limited. Hazard model validation and social vulnerability assessment deserve particular attention. New technologies offer great potential for engaging people and facilitating the coproduction of knowledge.
\end{abstract}

Keywords Crowdsourcing - Disaster risk reduction - Flood resilience - Social media - Volunteered geographic information (VGI)

\section{Introduction}

Climate-related hazards such as flooding, droughts, and windstorms are collectively responsible for the majority of recent disaster losses globally (IPCC 2012; UNISDR 2015)

Ian McCallum

mccallum@iiasa.ac.at

International Institute for Applied Systems Analysis (IIASA), 2361 Laxenburg, Lower Austria, Austria

2 Practical Action Consulting South Asia, Kathmandu, Nepal

3 Practical Action Latin America, Lima, Peru

4 Zurich Insurance Group, 8022 Zurich, Switzerland with floods affecting more people globally than any other type of natural disaster. This is partially a result of the rising trend in urbanization, which is altering land use and increasing the number of people living in areas that are highly exposed to the effects of natural hazards, such as communities located in river basins and coastal areas (Mileti 1999; Hallegatte 2011; GFDRR 2015).

Understanding and addressing each component of risk, and their interactions, is essential for effective flood disaster risk reduction (DRR). Technologies such as crowdsourcing [literally defined as outsourcing tasks to the crowd (Howe 2006)] is increasingly playing a role in DRR. In addition, social media services such as Twitter and Facebook are frequently used to monitor public reaction to floods, earthquakes, and fires (Abel et al. 2012; Earle et al. 2012; Kongthon et al. 2012), and volunteered geographic information (VGI) tools are now frequently used to complement official channels of humanitarian relief operations, as seen in the 2010 Haiti Earthquake (Norheim-Hagtun and Meier 2010; Zook et al. 2010), Hurricane Sandy in New York, 2012 (Schnebele et al. 2014), and the 2015 Nepal Earthquake (Clark 2015). The decentralized nature of disaster response and recovery makes new technologies a valuable tool for local monitoring and coordination and this is especially relevant in the area of ex-ante risk reduction. In this article, we outline recent technological applications in DRR and identify important areas for further engagement of technologies in reducing flood risk.

\section{Technologies and Flood Disaster Risk Reduction}

Flood risk may be defined as a function of hazard, exposure, and vulnerability (Cardona et al. 2012) and new technologies are revolutionizing the way in which 
information is collected and analyzed for each of these components (Jung 2011; Gómez et al. 2013; Poblet et al. 2014). Flood risk reduction takes place at different spatial scales, from local to global, with the scale of assessment often driving data requirements. Global mapping efforts such as Aqueduct and near-real-time early warning such as the Global Flood Awareness System (GloFAS) exist, but scales are often too coarse to be applied locally and empirical validation remains a challenge. In general, community level information is notoriously difficult to obtain, yet this is typically the focal scale of flood impacts and interventions.

Traditionally, community level information has been collected at the community level by nongovernmental organizations (NGOs), governments, and others in flood risk zones using participatory methods such as Participatory Vulnerability and Capacity Assessment (PVCA) resulting in a variety of different products, for example, maps of hazard, flood extent, exposure, and risk (Fig. 1a). While this information is the necessary catalyst, it quickly becomes outdated and is difficult to merge with other information or to share with donors or other stakeholders. Efforts to digitize this information are under way (Fig. 1b), achieving their greatest impact if the results are placed into shared open databases online, for example, OpenStreetMap (OSM) (Fig. 2) (Kienberger 2014; de Andrade and Szlafsztein 2015; Chingombe et al. 2015; Thaler and LevinKeitel 2016).

While extensive community-scale data are available in industrial countries and the more developed areas of the developing world, data deficiency is still a major obstacle to effective flood risk management across much of the developing world. The governments of many least developed countries (for example, Haiti and Nepal) usually have low human and technological capacity in disaster risk monitoring, but the emergence and popularization of mobile technology usage across the developing world is changing this. As a result, new technologies are now widely employed in flood response and recovery. The potential for these technologies gained international attention in the context of the catastrophic 2010 Haiti Earthquake where humanitarian responders had little or no

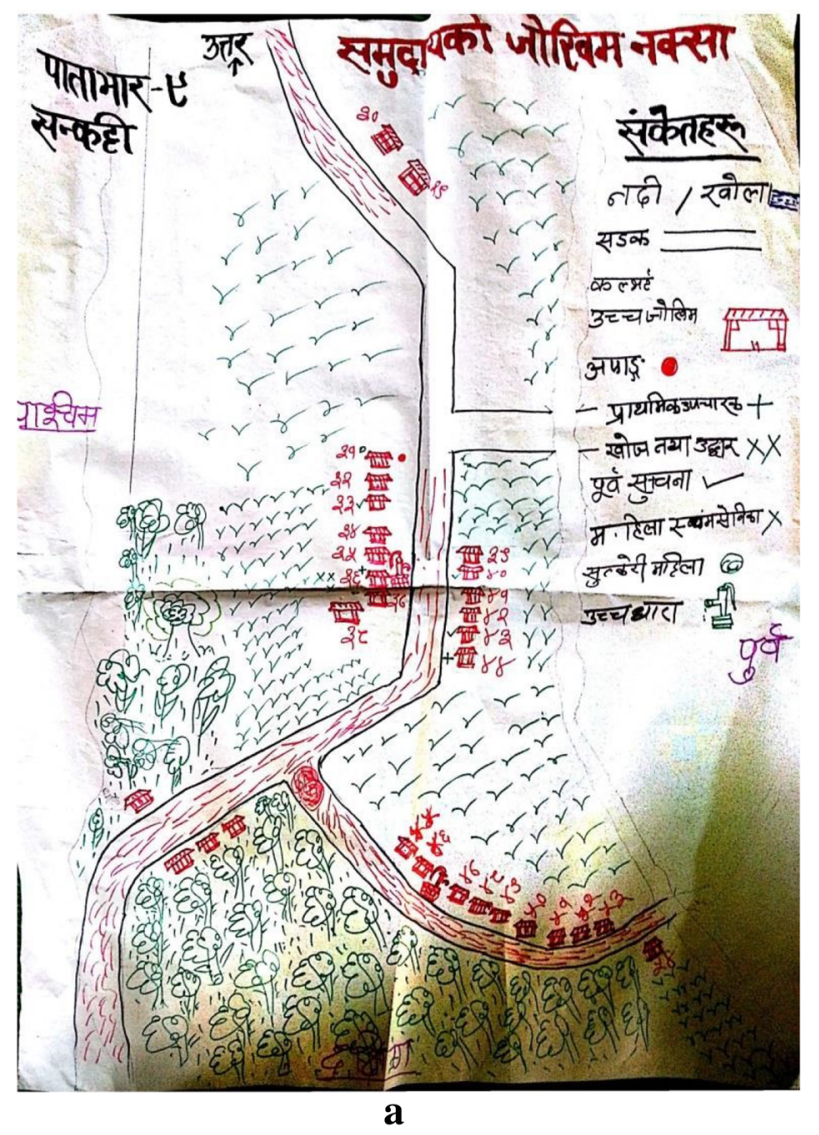

Fig. 1 a A Community flood risk map created by residents in the Sankatti community in the Karnali River basin, Nepal as part of an NGO-initiated, community-based vulnerability assessment conducted

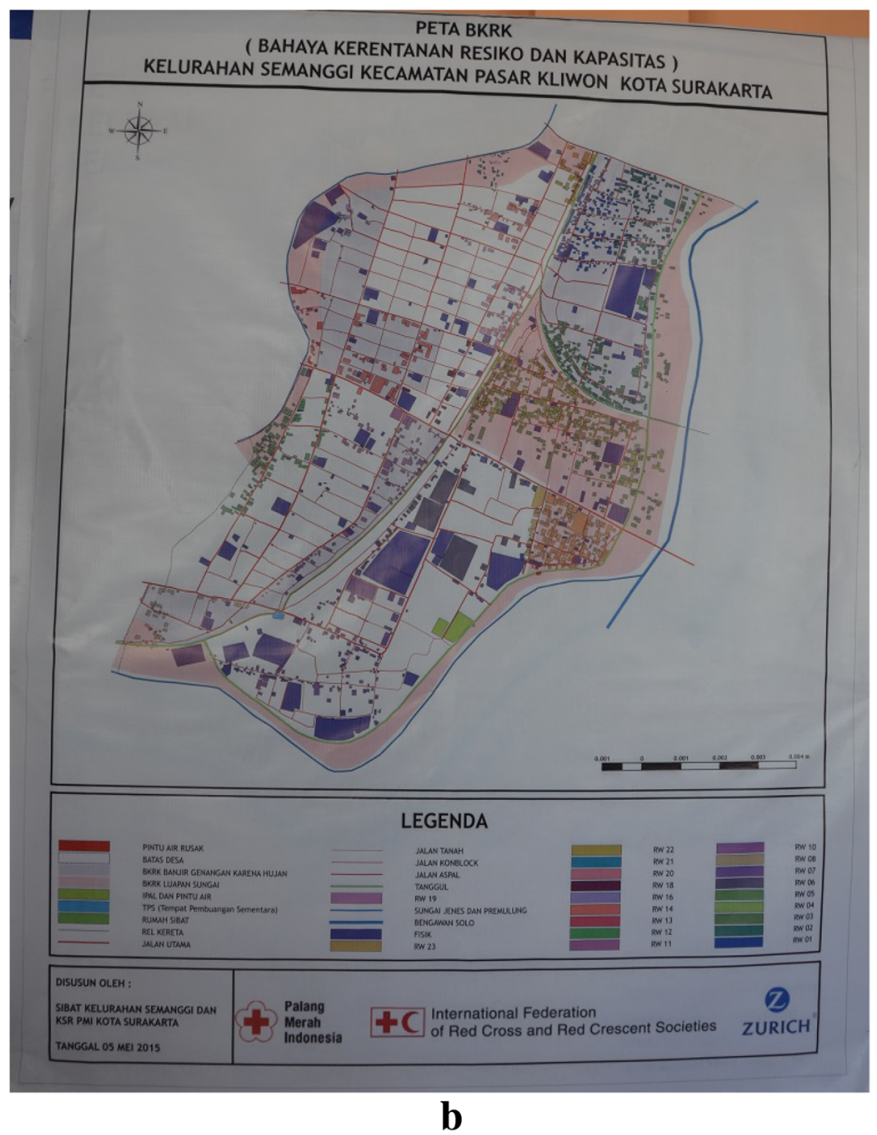

by Practical Action; b GIS-based risk map made by the Indonesian Red Cross Society, Palang Merah Indonesia (PMI) in the Bengawan River basin, Central Java, Indonesia 


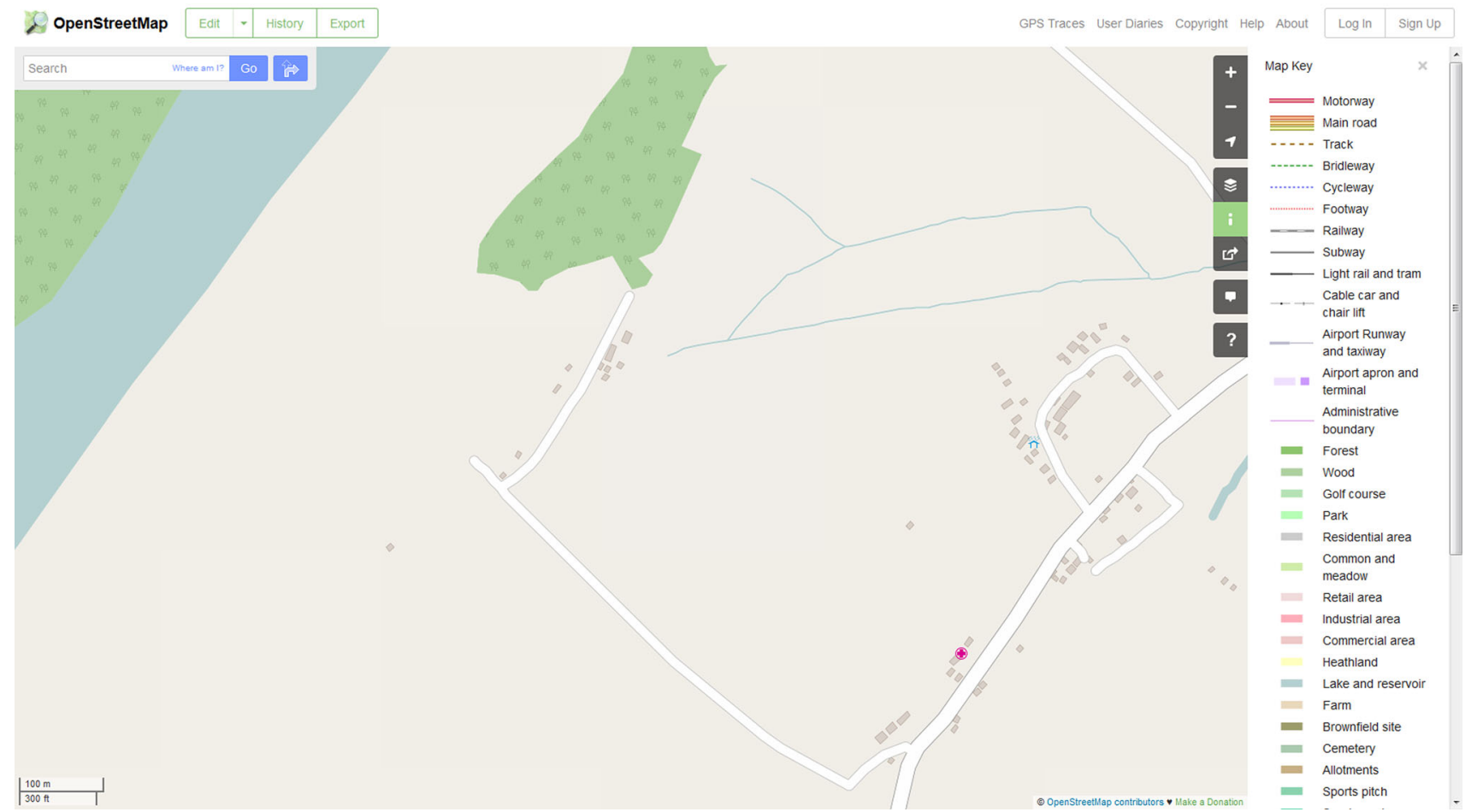

Fig. 2 The result of digitizing social, risk, and capacity maps into OSM for the Chakkhapur village, Rajapur Municipality, Bardiya District in the Karnali basin, Nepal. In addition to housing units, the local first aid and emergency shelter are indicated

access to detailed maps. Voluntary contributors rapidly began mapping road networks using satellite images and OSM-an effort later known as the Humanitarian OpenStreetMap Team (HOT). They went on to include baseline (transportation, education, health, water and sanitation facilities), humanitarian (hurricane disaster shelters and cholera-response structures), and community mapping as well as capacity building programs. In recent years, global initiatives such as the Standby Task Force and Digital Humanitarian Network are also harnessing the power of near-real-time mapping to support humanitarian response efforts. However, the application of technologies in ex-ante risk reduction is still limited, in particular in assessing critical risk factors-hazards and vulnerability. The following sections review the state of technologies used and identify important areas for further application in community flood risk management.

\subsection{Hazard}

To supplement traditional community-level participatory approaches such as PVCA, mobile phones are increasingly being used for the collection of data on flood events, for example, asking communities and/or NGOs to document the height that the flood level has reached and where the flooding has occurred or is occurring in real time. This type of information is revolutionizing the speed and ways in which the outputs of a hydrodynamic model may be validated. For example, the PetaJakarta twitter application in Jakarta, Indonesia collected 150,000 tweets within $24 \mathrm{~h}$ of the onset of flooding on 5 February 2014, dynamically mapping where floods occurred across the city (Holderness and Turpin 2015). Patterns of mobile use can also give similar clues as to which regions are impacted most severely by flooding (Pastor-Escuredo et al. 2014). In these studies, mobile phone usage was seen to increase in areas hardest hit by flooding. These technologies may be used to complement, validate, or even replace flood mapping undertaken by other, more traditional means. For example, crowdsourcing strategies costing as little as USD 60 may yield information equivalent to a conventional gauging station costing as much as USD 15,000 (Lowry and Fienen 2013).

\subsection{Exposure}

Mapping of exposed elements from the community up to the global level is possible through efforts such as OSM (for example, HOT and Missing Maps) and this is where a large portion of efforts have been targeted globally. Participatory and large-scale community mapping of exposed assets such as schools, hospitals, and other public 
and private buildings now exist in many areas across the globe, including developing countries such as the Philippines, Indonesia, Nepal, and South Sudan (GFDRR 2014). Successful engagement of local human resources-including universities, NGOs and residents-is key to effective collection of information. A variety of mobile applications exist that allow for the collection of in situ information related to infrastructure (for example, GPSLogger for Android devices and Pushpin OSM for Apple devices) with subsequent direct import into OSM. For effective flood risk reduction, it is desirable to create a detailed map in which the spatial distribution of the elements at risk are delineated, although a thorough assessment is often difficult and expensive due to the sheer number of the elements that should be considered (Hochrainer 2006).

\subsection{Vulnerability}

Vulnerability (divided into physical and socioeconomic aspects) is crucial for flood risk assessment, but is particularly poorly understood and quantified (Mechler and Bouwer 2014). Many vulnerability assessments undertaken in low-income, at-risk communities are focused on raising risk awareness and developing organizational capacity, and only a few local studies and assessments have used systematic techniques for recording, generating, and analyzing data (Government Office for Science 2012). Physical vulnerability is strongly linked to exposure and hence easier to determine. For example, building taxonomies are needed that describe the characteristics of individual buildings or a class of building with similar characteristics. A recent effort such as the Community Based Early Warning System at the Búzi River in Central Mozambique is conducting community-level physical vulnerability mapping (Kienberger 2014).

Efforts to quantify socioeconomic vulnerability are extremely limited, and information of this kind is rarely integrated into risk assessments (GFDRR 2014). Studies such as Helgeson et al. (2013) and Enenkel et al. (2015) are exceptions, having recorded socioeconomic vulnerability such as the incidence of malnutrition ex-ante within affected communities through geospatial surveys using, for example, Open Data Kit (ODK) or Geographical ODK (GeoODK). Given the cost-effectiveness and ease of implementation offered by many of these mobile technologies, vulnerability surveys may be easily repeated over time, greatly facilitating the tracking of long-term changes in socioeconomic vulnerability, as well as the detection of adaptation behaviors that become increasingly important in the context of altering patterns of flood risks and climate change adaptation.

\section{Toward User-Centric Flood Risk Assessment}

Community knowledge and feedback is essential in improving flood risk assessment and risk reduction interventions. Increasingly, development and humanitarian organizations working in the field of disaster risk reduction and climate change adaptation are using new technologies to facilitate data collection and monitoring (GFDRR 2014). In this context, the idea of "group-sourcing" or "expertsourcing," that is, information collected by trained individuals by means of mobile technologies (Enenkel et al. 2015) may complement these community interventions.

Besides mapping critical spatial information through PVCA, for example, open-source tools like ODK are extensively used for collecting and sharing information on socioeconomic vulnerability of communities and the disaster risks they face. For example, ODK was used in Indonesia by the community-based disaster preparedness team (SIBAT) and volunteers of PMI to conduct baseline surveys in thousands of households from 21 communities in three river basins. Information collected includes the local people's living, health, environment, and disaster history and was used to assist in flood risk mitigation decision-making processes. Unlike a conventional paperbased survey, this mobile-based survey system has been quicker, more accurate, cost-effective, and easier to analyze. ODK has also been linked with InaSAFE (software that produces realistic natural hazard impact scenarios for better planning, preparedness, and response activities) by the same groups of SIBAT members and volunteers to map actual information about river area, housing, livelihood, vulnerable areas, and evacuation routes at community and regional scales to make spatially explicit risk maps. These preliminary but effective efforts have the potential to be replicated throughout the country to establish a nationwide database on disaster risk and community vulnerabilities.

Furthermore, the global Zurich Flood Resilience Alliance has established the Risk Geo-Wiki effort, a branch of the Geo-Wiki application (See et al. 2016), allowing for the sharing of data and information gathered by communities, NGOs, the private sector, and research institutions. A key gap that is being tackled is to produce actionable preevent information on risk, in particular on physical and socioeconomic vulnerability. For example, the approach and process can be used to provide information on physical vulnerability (level of flooding for a certain flood intensity), which is essential for developing local stage-damage curves (Moel et al. 2015). Additionally, the approach can be used to survey and validate latent resilience properties, such as socioeconomic characteristics of households and communities. In fact, a large focus of the global Zurich Flood Resilience Alliance involves measuring resilience 
Fig. 3 Examples (outer ring) of technologies and tools in the disaster management space. Relief typically relies on social media tools, along with crowdsourcing and VGI. Recovery and reconstruction tools are often reactive, with predisaster tools typically proactive

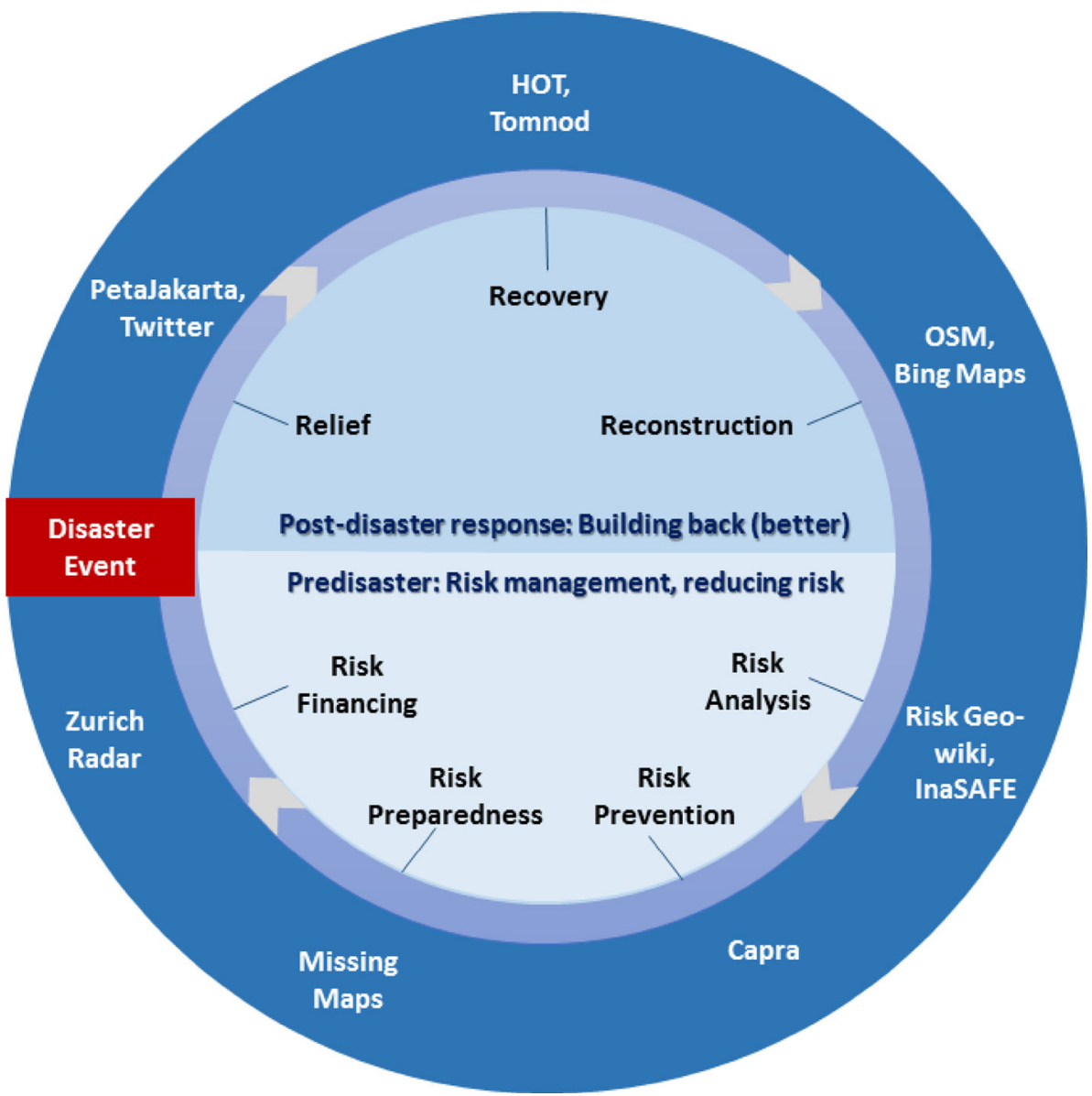

and implementing a scorecard approach, which will be subjected to in situ validation via a crowdsourcing approach.

\section{Conclusion}

With a growing number of technologies available to aid flood disaster risk reduction, we have considered a selection of these across the disaster management cycle (Fig. 3). Post-disaster response begins with relief efforts that typically utilize social media (for example, Twitter) and various forms of crowdsourcing and VGI. Shifting to recovery efforts, tools such as HOT and Tomnod (a high-resolution satellite imagery-based crowdsourcing tool) are followed by reconstruction needs that often rely on more reactive tools (for example, OSM with Bing Maps). Predisaster efforts tend to involve increasingly proactive technologies (for example, Risk Geo-Wiki, InaSAFE, CAPRA (the Central American Probabilistic Risk Assessment), Missing Maps (mapping the most vulnerable places in the developing world, in order that international and local NGOs and individuals can use the maps and data to better respond to crises), and Zurich Radar (the Zurich Radar for Natural Hazards allows for conducting a solid site and property analysis for real estate in Switzerland, based on hazard index maps).

While increasing use is being made of new technologies ex-post in disaster response and recovery, large potential lies in the application of these technologies ex-ante in disaster-prone regions. In particular, efforts that capture the newly acquired information in open databases (for example, OSM) offer multiple benefits beyond just the natural hazard community. While the demand is growing for disaster preparedness solutions, numerous barriers remain, including a lack of technical capacity and perhaps most importantly a lack of awareness of existing technologies.

Acknowledgments Funding from the global Zurich Flood Resilience Alliance is gratefully acknowledged. We thank Andreas Tanadi and Arfik Triwahyudi from Zurich Insurance Indonesia for providing detailed information on the implementation of the Community Flood Resilience Program in Indonesia.

Open Access This article is distributed under the terms of the Creative Commons Attribution 4.0 International License (http://crea tivecommons.org/licenses/by/4.0/), which permits unrestricted use, 
distribution, and reproduction in any medium, provided you give appropriate credit to the original author(s) and the source, provide a link to the Creative Commons license, and indicate if changes were made.

\section{References}

Abel, F., C. Hauff, G.-J. Houben, R. Stronkman, and K. Tao. 2012. Twitcident: Fighting fire with information from social web streams. In Proceedings of the 21st International Conference Companion on World Wide Web, 305-308. WWW'12 Companion. Lyon, France: Association for Computing Machinery. doi: $10.1145 / 2187980.2188035$.

Cardona, O.D., M.K. van Aalst, J. Birkmann, M. Fordham, G. McGregor, R. Perez, R.S. Pulwarty, E.L.F. Schipper, and B.T. Sinh. 2012. Determinants of risk: Exposure and vulnerability. In Managing the risks of extreme events and disasters to advance climate change adaption. A special report of the Working Groups I and II of the Intergovernmental Panel on Climate Change, ed. C.B. Field, V. Barros, T.F. Stocker, D. Qin, D.J. Dokken, K.L. Ebi, M.D. Mastrandrea, et al., 65-108. Cambridge and New York: Cambridge University Press.

Chingombe, W., E. Pedzisai, D. Manatsa, G. Mukwada, and P. Taru. 2015. A participatory approach in GIS data collection for flood risk management, Muzarabani district, Zimbabwe. Arabian Journal of Geosciences 8(2): 1029-1040.

Clark, L. 2015. How Nepal's earthquake was mapped in 48 hours. Wired UK. http://www.wired.co.uk/news/archive/2015-04/28/ mapping-nepal-after-the-earthquake. Accessed 23 May 2016.

de Andrade, M.M.N., and C.F. Szlafsztein. 2015. Community participation in flood mapping in the Amazon through interdisciplinary methods. Natural Hazards 78(3): 1491-1500.

Earle, P.S., D.C. Bowden, and M. Guy. 2012. Twitter earthquake detection: Earthquake monitoring in a social world. Annals of Geophysics 54(6): 708-715.

Enenkel, M., L. See, M. Karner, M.D. Alvarez, E. Rogenhofer, C. Baraldes, C. Lanusse, and N. Salse. 2015. Food security monitoring via mobile data collection and remote sensing: Results from the Central African Republic. PLoS One 10(11): e0142030.

GFDRR (Global Facility for Disaster Reduction and Recovery). 2014. Understanding risk: The evolution of disaster risk assessment. http://www.drrinacp.org/sites/drrinacp.org/files/publication/_ Understanding_Risk-Web_Version-rev_1.7.3.pdf. Accessed 23 May 2016.

GFDRR (Global Facility for Disaster Reduction and Recovery). 2015. Bringing resilience to scale, GFDRR Annual Report'14. Washington, DC: GFDRR. https://www.gfdrr.org/sites/gfdrr/files/ publication/GFDRR\%20ANNUAL\%20REPORT\%202014.pdf. Accessed 23 May 2016.

Gómez, D., A.M. Bernardos, J.I. Portillo, P. Tarrío, and J.R. Casar. 2013. A review on mobile applications for citizen emergency management. In Highlights on practical applications of agents and multi-agent systems, ed. J.M. Corchado, J. Bajo, J. Kozlak, P. Pawlewski, J. M. Molina, V. Julian, R.A. Silveira, R. Unland, and S. Giroux, 190-201. Berlin: Springer.

Government Office for Science. 2012. Foresight reducing risks of future disasters: Priorities for decision makers. Executive Summary. London: The Government Office for Science. https://www.gov.uk/government/uploads/system/uploads/attach ment_data/file/286480/12-1322-reducing-risks-of-future-disasterssummary.pdf. Accessed 23 May 2016.

Hallegatte, S. 2011. How economic growth and rational decisions can make disaster losses grow faster than wealth. Policy research working paper. Washington, DC: World Bank.
Helgeson, J.F., S. Dietz, and S. Hochrainer-Stigler. 2013. Vulnerability to weather disasters: The choice of coping strategies in rural Uganda. Ecology and Society 18(2): Article no. 2. doi:10. 5751/ES-05390-180202.

Hochrainer, S. 2006. Macroeconomic risk management against natural disasters. Wiesbaden: German University Publisher.

Holderness, T., and E. Turpin. 2015. PetaJakarta.org: Assessing the role of social media for civic co-management during monsoon flooding in Jakarta, Indonesia. White paper. SMART Infrastructure Facility, University of Wollongong.

Howe, J. 2006. The rise of crowdsourcing. Wired Magazine 14(6): 1-4. IPCC (Intergovernmental Panel on Climate Change). 2012. Managing the risks of extreme events and disasters to advance climate change adaptation. A special report of Working Groups I and II of the Intergovernmental Panel on Climate Change. ed. C.B. Field, V. Barros, T.F. Stocker, D. Qin, D.J. Dokken, K.L. Ebi, M.D. Mastrandrea, et al. Cambridge and New York: Cambridge University Press.

Jung, C. 2011. Mobile data collection systems: A review of the current state of the field. Centre National d'Etudes Spatiales. http:// www.parkdatabase.org/files/documents/nomad_mdc_research. pdf. Accessed 23 May 2016.

Kienberger, S. 2014. Participatory mapping of flood hazard risk in Munamicua, District of Búzi, Mozambique. Journal of Maps 10(2): 269-275.

Kongthon, A., C. Haruechaiyasak, J. Pailai, and S. Kongyoung. 2012. The role of Twitter during a natural disaster: Case study of 2011 Thai flood. In 2012 Proceedings of PICMET'12: Technology Management for Emerging Technologies, 29 July-2 August 2012, Vancouver, BC, 2227-2232.

Lowry, C.S., and M.N. Fienen. 2013. CrowdHydrology: Crowdsourcing hydrologic data and engaging citizen scientists. Ground Water 51(1): 151-156.

Mechler, R., and L.M. Bouwer. 2014. Understanding trends and projections of disaster losses and climate change: Is vulnerability the missing link? Climatic Change 133(1): 23-35.

Mileti, D. 1999. Disasters by design: A reassessment of natural hazards in the United States. Washington, DC: Joseph Henry Press.

Moel, H., B. Jongman, H. Kreibich, B. Merz, E. Penning-Rowsell, and P.J. Ward. 2015. Flood risk assessments at different spatial scales. Mitigation and Adaptation Strategies for Global Change 20(6): 865-890.

Norheim-Hagtun, I., and P. Meier. 2010. Crowdsourcing for crisis mapping in Haiti. Innovations: Technology, Governance, Globalization 5(4): 81-89

Pastor-Escuredo, D., A. Morales-Guzman, Y. Torres-Fernandez, J.-M. Bauer, A. Wadhwa, C. Castro-Correa, L. Romanoff, J.G. Lee, A. Rutherford, V. Frias-Martinez, N. Oliver, E. Frias-Martinez, and M. Luengo-Oroz. 2014. Flooding through the lens of mobile phone activity. In Proceedings of the IEEE Global Humanitarian Technology Conference, 10-13 October 2014, San Jose, CA, 279-286.

Poblet, M., E. García-Cuesta, and P. Casanovas. 2014. Crowdsourcing tools for disaster management: A review of platforms and methods. In AI Approaches to the Complexity of Legal Systems, ed. P. Casanovas, U. Pagallo, M. Palmirani, and G. Sartor, 261-274. Berlin: Springer.

Schnebele, E., G. Cervone, and N. Waters. 2014. Road assessment after flood events using non-authoritative data. Natural Hazards and Earth System Science 14: 1007-1015.

See, L., P. Mooney, G. Foody, L. Bastin, A. Comber, J. Estima, S. Fritz, et al. 2016. Crowdsourcing, citizen science or volunteered geographic information? The current state of crowdsourced geographic information. ISPRS International Journal of GeoInformation 5(5): Article no. 55. doi:10.3390/ijgi5050055. 
Thaler, T., and M. Levin-Keitel. 2016. Multi-level stakeholder engagement in flood risk management-A question of roles and power: Lessons from England. Environmental Science \& Policy 55: 292-301.

UNISDR (United Nations International Strategy for Disaster Reduction). 2015. Making development sustainable: The future of disaster risk management. Global assessment report on disaster risk reduction. Geneva: UNISDR.

Zook, M., M. Graham, T. Shelton, and S. Gorman. 2010. Volunteered geographic information and crowdsourcing disaster relief: A case study of the Haitian earthquake. World Medical \& Health Policy 2(2): 7-33. 